Mar. Drugs 2011, 9, 369-381; doi:10.3390/md9030369

OPEN ACCESS

Marine Drugs

ISSN 1660-3397

www.mdpi.com/journal/marinedrugs

Article

\title{
Chemical Screening Method for the Rapid Identification of Microbial Sources of Marine Invertebrate-Associated Metabolites
}

\author{
Fabrice Berrue $^{\dagger}$, Sydnor T. Withers ${ }^{\dagger}$, Brad Haltli, Jo Withers and Russell G. Kerr *
}

Department of Chemistry \& Department of Biomedical Sciences, Atlantic Veterinary College, University of Prince Edward Island, Charlottetown, PEI, Canada; E-Mails: fberrue@ upei.ca (F.B.); sydwithers@gmail.com (S.T.W.); bhaltli@ upei.ca (B.H.); jo.withers@yahoo.com (J.W.)

$\dagger$ These authors contributed equally to this work.

* Author to whom correspondence should be addressed; E-Mail: rkerr@ upei.ca;

Tel.: +1-902-566-0565; Fax: +1-902-566-7445.

Received: 4 February 2011; in revised form: 6 March 2011 / Accepted: 18 March 2011 /

Published: 21 March 2011

\begin{abstract}
Marine invertebrates have proven to be a rich source of secondary metabolites. The growing recognition that marine microorganisms associated with invertebrate hosts are involved in the biosynthesis of secondary metabolites offers new alternatives for the discovery and development of marine natural products. However, the discovery of microorganisms producing secondary metabolites previously attributed to an invertebrate host poses a significant challenge. This study describes an efficient chemical screening method utilizing a 96-well plate-based bacterial cultivation strategy to identify and isolate microbial producers of marine invertebrate-associated metabolites.
\end{abstract}

Keywords: chemical screening; coral-associated bacteria; UPLC/MS; gorgonian coral

\section{Introduction}

Marine invertebrates are a well recognized source of new bioactive natural products with substantial potential for development as human therapeutics [1-7]. Despite the great potential of many natural products derived from marine invertebrates, the realization of this potential is frequently hindered by the inability of the natural source to provide sufficient quantities of the bioactive component to support 
traditional drug testing and development activities [8]. This "supply issue" is one of the greatest challenges facing the development of marine natural products.

There is a growing recognition that microorganisms associated with marine invertebrate hosts play an important role in the biosynthesis of secondary metabolites. As such, this could offer a new alternative to the production of potential drug-leads isolated from marine invertebrates $[7,9,10]$. Indeed, culturing invertebrate-associated microbes responsible for natural product biosynthesis would provide one approach to develop a sustainable supply of marine natural product leads [11]. However, the discovery of microorganisms producing secondary metabolites previously attributed to an invertebrate host has thus far, met with only modest success [12-14]. The isolation and cultivation of microbial symbionts remains as a significant challenge due to their potential dependence on host supplied factors for growth and secondary metabolite production [7,10].

This report describes a novel chemically oriented screen based on ultra high performance liquid chromatography/mass spectrometry (UPLC/MS) to direct the isolation of invertebrate-associated microorganisms implicated in the biosynthesis of secondary metabolites previously identified from the host invertebrate. This contrasts with the more conventional approach of prioritizing microbial isolates based on phylogenetic analysis and bioassay data. While this traditional approach is clearly of value, this provides only limited information on the ability of the isolates to produce novel secondary metabolites. A traditional chemical analysis of microbial culture extracts is of obvious value; however, this typically is a slow, tedious process. Herein, we describe a high-throughput chemically guided microbial isolation strategy which is facilitated by performing mixed bacterial cultures in a 96 multi-well plate (MWP) format and the use of new UPLC/MS technology as a rapid chemical screening tool. The high-throughput nature of the MWPs greatly facilitated the parallel investigation of multiple growth conditions while also greatly accelerating the chemical screening of MWP cultures [15]. The MWPs are employed for three separate culturing steps: (1) growth of mixed bacterial cultures derived from coral homogenate inocula in multiple media conditions, (2) growth of axenic cultures purified from mixed bacterial assemblages, and (3) optimization of media conditions to maximize yields of target compounds produced by bacteria purified from mixed cultures.

A chemical screening strategy can benefit from the use of standards (or target-molecules) which can be rapidly characterized by diagnostic parameters. Our approach utilizing UPLC/MS thus used retention time and MS data. Thus, the initial step of the study was a UPLC/MS investigation of the gorgonian coral Erythropodium caribaeorum (EC) in order to create an UPLC/MS library of target-molecules. EC was selected as a representative coral as it is abundant in many regions of the Caribbean and is known to possess a rich diversity of secondary metabolites [16-20]. MWP cultures of mixed microbial populations derived from coral homogenate inocula were performed in multiple growth conditions. Factors controlling secondary metabolite production in complex marine microorganism-invertebrate assemblages are largely unknown and thus we endeavored to expose the inoculated bacteria to a vast array of culture conditions which would hopefully allow for the establishment of an equally diverse number of cultures, thus increasing our chances of identifying a culture producing an EC metabolite. A 96 MWP format was utilized for the growth of axenic cultures purified from selected mixed microbial assemblages to identify the microbial producers of three secondary metabolites previously found in the gorgonian EC and secondly, to maximize production yield. 


\section{Results and Discussion}

\subsection{UPLC/MS Library of EC Secondary Metabolites}

A UPLC/MS library of metabolites from EC was established to provide "standards" for the chemical screening of mixed bacterial cultures derived from EC tissue homogenates. Each member of the library was characterized by retention time, full MS and tandem MS/MS data of the most abundant ion using a standardized method. While the goal was not to identify each component of this mixture, amongst the 82 metabolites characterized in this manner, a few components could be readily identified by comparison with published data. The most abundant secondary metabolites present in EC extracts, erythrolides A and B (RT 2.05 min, 419.2 amu and RT $2.16 \mathrm{~min}, 479.1 \mathrm{amu}$, respectively) [16], were readily detected as were the potent antimitotic compounds, eleutherobin and desmethyleuleutherobin (RT 2.04 min, 657.2 amu, RT $1.69 \mathrm{~min}, 643.3 \mathrm{amu}$, respectively) [19].

\subsection{Screening Mixed Cultures for "EC Metabolites"}

The chemical diversity of EC is evident by the large number of metabolites readily detected by UPLC/MS. A mixed culture strategy employing a small scale 96 MWP growth format was used to query the relationship between the chemical diversity observed in EC extracts and the microbial community associated with this gorgonian. Employing this format, a homogenized EC tissue preparation was used to inoculate 1536 different culture conditions in order to expose the mixed microbial community to a variety of selective pressures and an array of nutritional resources with which to support secondary metabolite biosynthesis. We subsequently applied the UPLC/MS chemical screen previously used to create the EC metabolite library to analyze each of the 1536 mixed cultures for the production of the 82 metabolites initially observed in the coral extract. Direct chemical screening of such large numbers of samples has only recently been made feasible with the advent of UPLC technology which allows for the analysis of a large number of samples in a short period of time while increasing sensitivity and resolution [21-23]. For example, one 96 MWP plate can be analyzed by UPLC/MS and the data processed (using a customized application from the software $\mathrm{Xcalibur}^{\mathrm{TM}}$ ), allowing for the quantification of the 82 metabolites in each well in approximately 10 hours.

Four enrichment plates with 96 different conditions as described in Table 1 were prepared, and inoculated with EC homogenate and incubated at $30{ }^{\circ} \mathrm{C}$ and $37{ }^{\circ} \mathrm{C}$ under both static and shaken (150 rpm) conditions. The MWPs contained a nutritionally diverse array of media which varied in carbon source, nitrogen source and $\mathrm{pH}$. The antibiotics penicillin $\mathrm{G}$ and kanamycin were added to select for the establishment of mixed cultures dominated by different groups of bacteria which exhibit natural resistance to these antibiotics. The goal of the enrichment plates was to generate a continuum of microbial diversity that could be further fermented and ultimately screened for the production of EC metabolites. 
Table 1. Enrichment plate layout.

\begin{tabular}{|c|c|c|c|c|c|c|c|c|c|c|c|c|}
\hline & \multicolumn{4}{|c|}{ No Antibiotics } & \multicolumn{4}{|c|}{ +Penicillin G } & \multicolumn{4}{|c|}{ +Kanamycin } \\
\hline & 1 & 2 & 3 & 4 & 5 & 6 & 7 & 8 & 9 & 10 & 11 & 12 \\
\hline $\mathbf{A}$ & NB & $\begin{array}{c}\text { NB } \\
\text { pH } 5.8 \\
\end{array}$ & $\begin{array}{c}1 / 10 \mathrm{NB} \\
\mathrm{pH} 5.8\end{array}$ & $\begin{array}{c}\text { MB } \\
\mathrm{pH} 5.8 \\
\end{array}$ & NB & $\begin{array}{c}\mathrm{NB} \\
\mathrm{pH} 5.8\end{array}$ & $\begin{array}{c}1 / 10 \mathrm{NB} \\
\mathrm{pH} 5.8\end{array}$ & $\begin{array}{c}\text { MB } \\
\text { pH } 5.8\end{array}$ & NB & $\begin{array}{c}\text { NB } \\
\text { pH } 5.8\end{array}$ & $\begin{array}{c}1 / 10 \mathrm{NB} \\
\mathrm{pH} 5.8\end{array}$ & $\begin{array}{c}\text { MB } \\
\text { pH } 5.8\end{array}$ \\
\hline B & LB & $\begin{array}{c}\text { NB } \\
\text { pH6.5 }\end{array}$ & $\begin{array}{c}1 / 10 \mathrm{NB} \\
\mathrm{pH} 6.5\end{array}$ & $\begin{array}{c}\text { MB } \\
\text { pH6.5 }\end{array}$ & LB & $\begin{array}{c}\text { NB } \\
\text { pH6.5 }\end{array}$ & $\begin{array}{c}1 / 10 \mathrm{NB} \\
\mathrm{pH} 6.5\end{array}$ & $\begin{array}{c}\text { MB } \\
\text { pH6.5 }\end{array}$ & LB & $\begin{array}{c}\text { NB } \\
\text { pH6.5 }\end{array}$ & $\begin{array}{c}1 / 10 \mathrm{NB} \\
\mathrm{pH} 6.5\end{array}$ & $\begin{array}{c}\mathrm{MB} \\
\mathrm{pH} 6.5\end{array}$ \\
\hline $\mathbf{C}$ & MB & $\begin{array}{c}\mathrm{NB} \\
\mathrm{pH} 7.2\end{array}$ & $\begin{array}{c}1 / 10 \mathrm{NB} \\
\mathrm{pH} 7.2 \\
\end{array}$ & $\begin{array}{c}\mathrm{MB} \\
\mathrm{pH} 7.2 \\
\end{array}$ & MB & $\begin{array}{c}\mathrm{NB} \\
\mathrm{pH} 7.2\end{array}$ & $\begin{array}{c}1 / 10 \mathrm{NB} \\
\mathrm{pH} 7.2\end{array}$ & $\begin{array}{c}\text { MB } \\
\mathrm{pH} 7.2\end{array}$ & MB & $\begin{array}{c}\mathrm{NB} \\
\mathrm{pH} 7.2\end{array}$ & $\begin{array}{c}1 / 10 \mathrm{NB} \\
\mathrm{pH} 7.2 \\
\end{array}$ & $\begin{array}{c}\text { MB } \\
\mathrm{pH} 7.2\end{array}$ \\
\hline D & $\mathrm{TB}$ & $\begin{array}{c}\mathrm{NB} \\
\mathrm{pH} 8.0\end{array}$ & $\begin{array}{c}1 / 10 \mathrm{NB} \\
\mathrm{pH} 8.0\end{array}$ & $\begin{array}{c}\mathrm{MB} \\
\mathrm{pH} 8.0\end{array}$ & TB & $\begin{array}{c}\mathrm{NB} \\
\mathrm{pH} 8.0\end{array}$ & $\begin{array}{c}1 / 10 \mathrm{NB} \\
\mathrm{pH} 8.0\end{array}$ & $\begin{array}{c}\mathrm{MB} \\
\mathrm{pH} 8.0\end{array}$ & $\mathrm{~TB}$ & $\begin{array}{c}\mathrm{NB} \\
\mathrm{pH} 8.0\end{array}$ & $\begin{array}{c}1 / 10 \mathrm{NB} \\
\mathrm{pH} 8.0\end{array}$ & $\begin{array}{c}\mathrm{MB} \\
\mathrm{pH} 8.0\end{array}$ \\
\hline $\mathbf{E}$ & $\mathrm{dH}_{2} \mathrm{O}$ & $\begin{array}{c}\text { ISP1 } \\
10 \mu \mathrm{g} / \mathrm{mL} \\
\text { NA }\end{array}$ & $\begin{array}{c}\mathrm{NB}+ \\
0.5 \% \\
\text { butanol }\end{array}$ & $\begin{array}{c}1 / 10 \mathrm{MB} \\
\mathrm{pH} 5.8\end{array}$ & $\mathrm{dH}_{2} \mathrm{O}$ & $\begin{array}{c}\text { ISP1 } \\
10 \mu \mathrm{g} / \mathrm{mL} \\
\text { NA }\end{array}$ & $\begin{array}{c}\mathrm{NB}+ \\
0.5 \% \\
\text { butanol }\end{array}$ & $\begin{array}{c}1 / 10 \mathrm{MB} \\
\mathrm{pH} 5.8\end{array}$ & $\mathrm{dH}_{2} \mathrm{O}$ & $\begin{array}{c}\text { ISP1 } \\
10 \mu \mathrm{g} / \mathrm{mL} \\
\text { NA }\end{array}$ & $\begin{array}{c}\mathrm{NB}+ \\
0.5 \% \\
\text { butanol }\end{array}$ & $\begin{array}{c}1 / 10 \mathrm{MB} \\
\mathrm{pH} 5.8\end{array}$ \\
\hline $\mathbf{F}$ & $\begin{array}{c}\text { M9 } \\
\text { glycerol }\end{array}$ & NB/SW & ASW & \begin{tabular}{|c|} 
1/10 MB \\
pH6.5 \\
\end{tabular} & $\begin{array}{c}\text { M9 } \\
\text { glycerol }\end{array}$ & $\mathrm{NB} / \mathrm{SW}$ & ASW & \begin{tabular}{|c|}
$1 / 10 \mathrm{MB}$ \\
$\mathrm{pH} 6.5$ \\
\end{tabular} & $\begin{array}{c}\text { M9 } \\
\text { glycerol }\end{array}$ & $\mathrm{NB} / \mathrm{SW}$ & ASW & $\begin{array}{c}1 / 10 \mathrm{MB} \\
\mathrm{pH} 6.5\end{array}$ \\
\hline $\mathbf{G}$ & $\begin{array}{c}\text { M9 } \\
\text { glucose }\end{array}$ & Emerson & $\begin{array}{c}\text { ASW } \\
\text { glycerol }\end{array}$ & \begin{tabular}{|c|} 
\\
1/10 MB \\
$\mathrm{pH} 7.2$
\end{tabular} & $\begin{array}{c}\text { M9 } \\
\text { glucose }\end{array}$ & Emerson & $\begin{array}{c}\text { ASW } \\
\text { glycerol }\end{array}$ & \begin{tabular}{|c|}
$1 / 10 \mathrm{MB}$ \\
$\mathrm{pH} 7.2$ \\
\end{tabular} & $\begin{array}{c}\text { M9 } \\
\text { glucose }\end{array}$ & Emerson & $\begin{array}{c}\text { ASW } \\
\text { glycerol }\end{array}$ & $\begin{array}{c}1 / 10 \mathrm{MB} \\
\mathrm{pH} 7.2 \\
\end{array}$ \\
\hline $\mathbf{H}$ & $\begin{array}{c}\text { M9 } \\
\text { arabinose }\end{array}$ & R2 Broth & $\begin{array}{c}\text { ASW } \\
\text { glucose }\end{array}$ & $\begin{array}{c}1 / 10 \mathrm{MB} \\
\mathrm{pH} 8.0\end{array}$ & $\begin{array}{c}\text { M9 } \\
\text { arabinose }\end{array}$ & R2 Broth & $\begin{array}{l}\text { ASW } \\
\text { glucose }\end{array}$ & $\begin{array}{c}1 / 10 \mathrm{MB} \\
\mathrm{pH} 8.0\end{array}$ & $\begin{array}{c}\text { M9 } \\
\text { arabinose }\end{array}$ & R2 Broth & $\begin{array}{c}\text { ASW } \\
\text { glucose }\end{array}$ & $\begin{array}{c}1 / 10 \mathrm{MB} \\
\mathrm{pH} 8.0\end{array}$ \\
\hline
\end{tabular}

Figure 1. Comparison of the MS/MS spectra of extracts derived from the mixed bacterial culture and the coral Erythropodium caribaeorum.
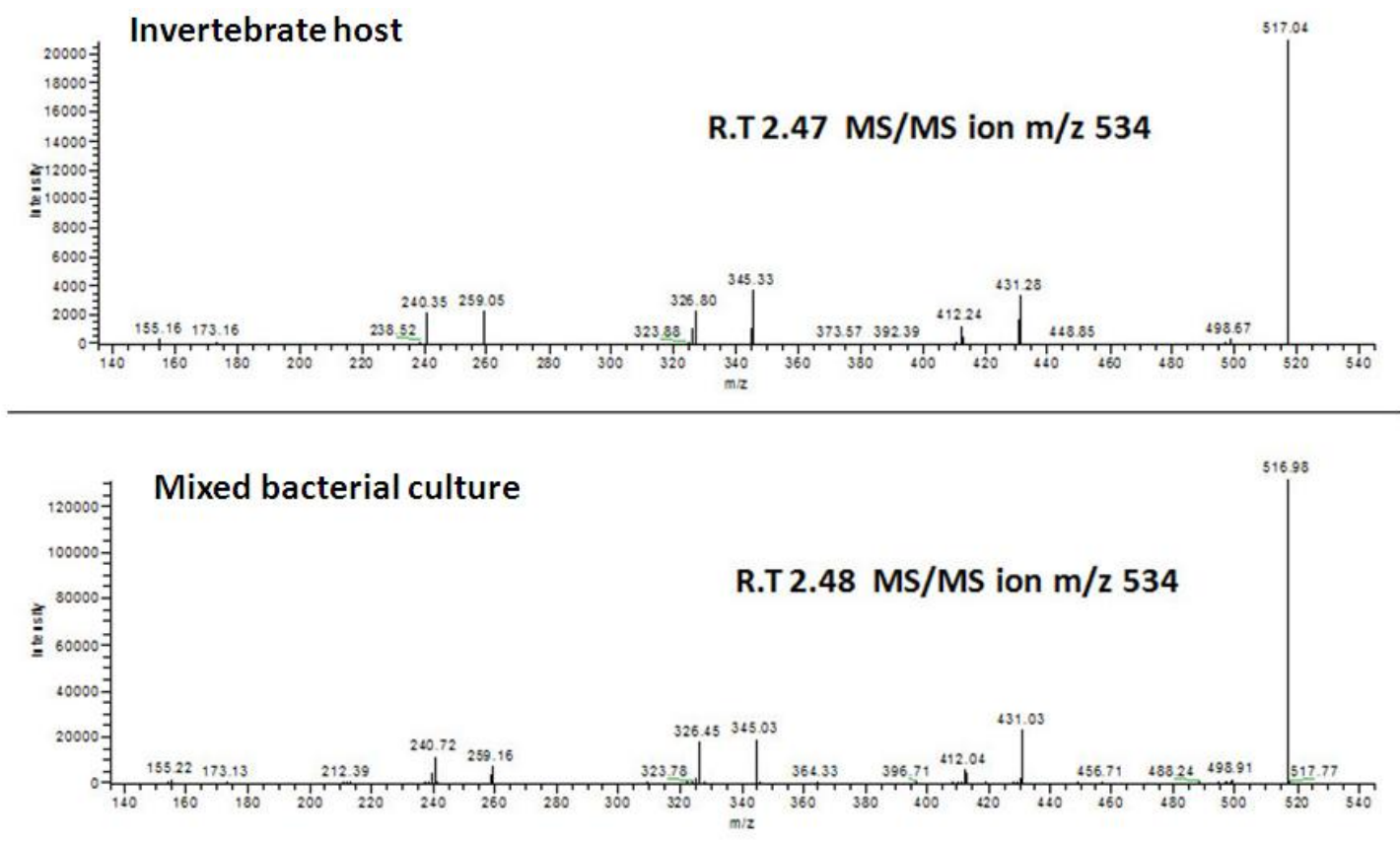

After 7 days, the 4 enrichment plates representing 384 different cultures were subcultured into four 96-MWPs containing either the same array of media as the enrichment plates, or uniformly filled with Terrific Broth (TB), Marine Broth (MB) or 1/10 MB medium. Subcultured plates were incubated for an additional 14 days at $30{ }^{\circ} \mathrm{C}$ under static conditions to allow for the accumulation of secondary 
metabolites in the mixed cultures. Glycerol stocks were prepared from the four enrichment plates and the remaining culture broths $(1.4 \mathrm{~mL})$ were extracted and analyzed by UPLC/MS employing the same method used to generate the EC metabolite library. After 14 days of incubation, glycerol stocks from the 16 subcultured MWPs were prepared and the remaining culture broths were analyzed by UPLC/MS, and compared to the EC metabolite library. Among the 82 metabolites, three target molecules, compounds 41 (RT $2.48 \mathrm{~min}, 534.4 \mathrm{amu}$ ), 47 (RT $2.59 \mathrm{~min}, 620.3 \mathrm{amu}$ ) and, 53 (2.75 min, $706.3 \mathrm{amu})$ were detected in two mixed cultures across the 16 MWPs analyzed. The matches between the EC metabolite library and the bacterial mixed culture experiments were confirmed by comparison of their MS/MS spectra (Figure 1). Moreover, the MS data of compounds 41, 47, and 53 indicated that these three compounds belonged to a family of metabolites which possess varying amounts of repeating units with a mass of $86 \mathrm{amu}$.

\subsection{Isolation and Identification of Pure Cultures Producing Target Compounds 41, $\mathbf{4 7}$ and $\mathbf{5 3}$}

While it was interesting to confirm production of natural products $\mathbf{4 1 , 4 7}$ and 53 in mixed cultures, our goal was to use the described strategy to obtain pure cultures capable of producing compounds identified in the 82-member coral metabolite library. Thus, the MWP chemical screening strategy was used to guide the isolation of the microbial producer by testing growth cultures of single isolates. To obtain pure isolates of the bacterial producers of target compounds $\mathbf{4 1}, \mathbf{4 7}$ and $\mathbf{5 3}$, glycerol stocks made from Subculture Plate 1 derived from Enrichment Plate 1 (plate 1-1) well D5 (TB medium + penicillin G) and Subculture Plate 1 derived from Enrichment Plate 2 (plate 2-1) well B1 (LB medium) were plated on TB agar and LB agar, respectively. Thirty six colonies were picked according their physical appearance and morphology and inoculated in $1.7 \mathrm{~mL}$ of NB, LB, TB, M9 glycerol and ASW glycerol media dispensed in a MWP. After 14 days at $30{ }^{\circ} \mathrm{C}$, the plates were extracted and analyzed by UPLC/MS. Three colonies isolated from plate 1-1 well D5 (E1-1D5g, E1-1D5i, and E1-1D5j) and two colonies isolated from plate 2-1 well B1 (E2-1B1a and E2-1B1d) revealed the presence of the target compounds. Isolates E1-1D5j and E1-1D5g exhibited strong production in TB medium. The targeted compounds were also detected in the relatively nutritionally lean medium ASW glycerol for colonies E1-1D5i and E2-1B1a. The production of the target metabolites by these cultures was further confirmed by tandem mass spectrometry.

\subsection{Structure Elucidation of Compounds $\mathbf{4 1 , 4 7}$ and 53}

The isolation and the identification of secondary metabolites from microorganisms often requires large culture volumes and multiple chromatographic steps in order to purify small amount of material from a complex mixture of microbial metabolites and media components. Our approach allowed us to rapidly identify and purify targeted compounds $(\mathbf{4 1}, \mathbf{4 7}$, and 53) from the EC extract using standard chromatographic techniques. Compound 47 was characterized by 1D and 2D NMR analysis as well as tandem mass spectroscopy and identified as an oligomer containing seven 3-hydroxybutyric acid units. Due to observed differences of 86 amu in the mass spectra, compounds $\mathbf{4 1}$ and $\mathbf{5 3}$ were determined to possess six and eight 3-hydroxybutyric acid units, respectively. 


\subsection{Media Optimization}

To further validate the utility of the MWP cultivation format and to identify improved conditions for the production of 41, 47 and $\mathbf{5 3}$ by EC isolates E1-1D5g, E1-1D5i, and E1-1D5j, a media study aimed at increasing metabolite yields was conducted. A full factorial approach to optimizing the TB media formulation was employed. Briefly, three arbitrary levels (low, medium and high) of the three primary nutritional media components (tryptone, yeast extract and glycerol) of TB medium were combined in all possible combinations, resulting in 27 media formulations which were dispensed in MWPs (Figure 2). Each of the 3 EC isolates were cultured in duplicate and the inoculated MWPs were incubated stationary for 14 days at $30{ }^{\circ} \mathrm{C}$. Cultures were extracted and analyzed by UPLC/MS using methodology identical to that used to screen initial mixed cultures. The results of the media study are summarized in Figure 2. Several alternative TB medium formulations were identified which supported titers of 41, 47 and $\mathbf{5 3} 1.3$ to 5.23 fold greater than those supported by the standard TB medium formulation (TB14). Examination of Figure 2 indicates that yeast extract and tryptone concentrations had the most profound effect on formation of 41, 47 and 53. Increasing concentrations of yeast extract clearly inhibited their formation as titers consistently decreased in response to increasing yeast extract levels. Conversely, titers exhibited an increasing trend in response to increasing concentrations of tryptone. In general mid-level glycerol concentrations appeared to support greater production levels than the high or low concentrations, however, the effect of glycerol on the yield of $\mathbf{4 1 , 4 7}$ and 53 was less pronounced than the effects of tryptone and yeast extract.

Figure 2. Results of Terrific Broth (TB) media optimization study.

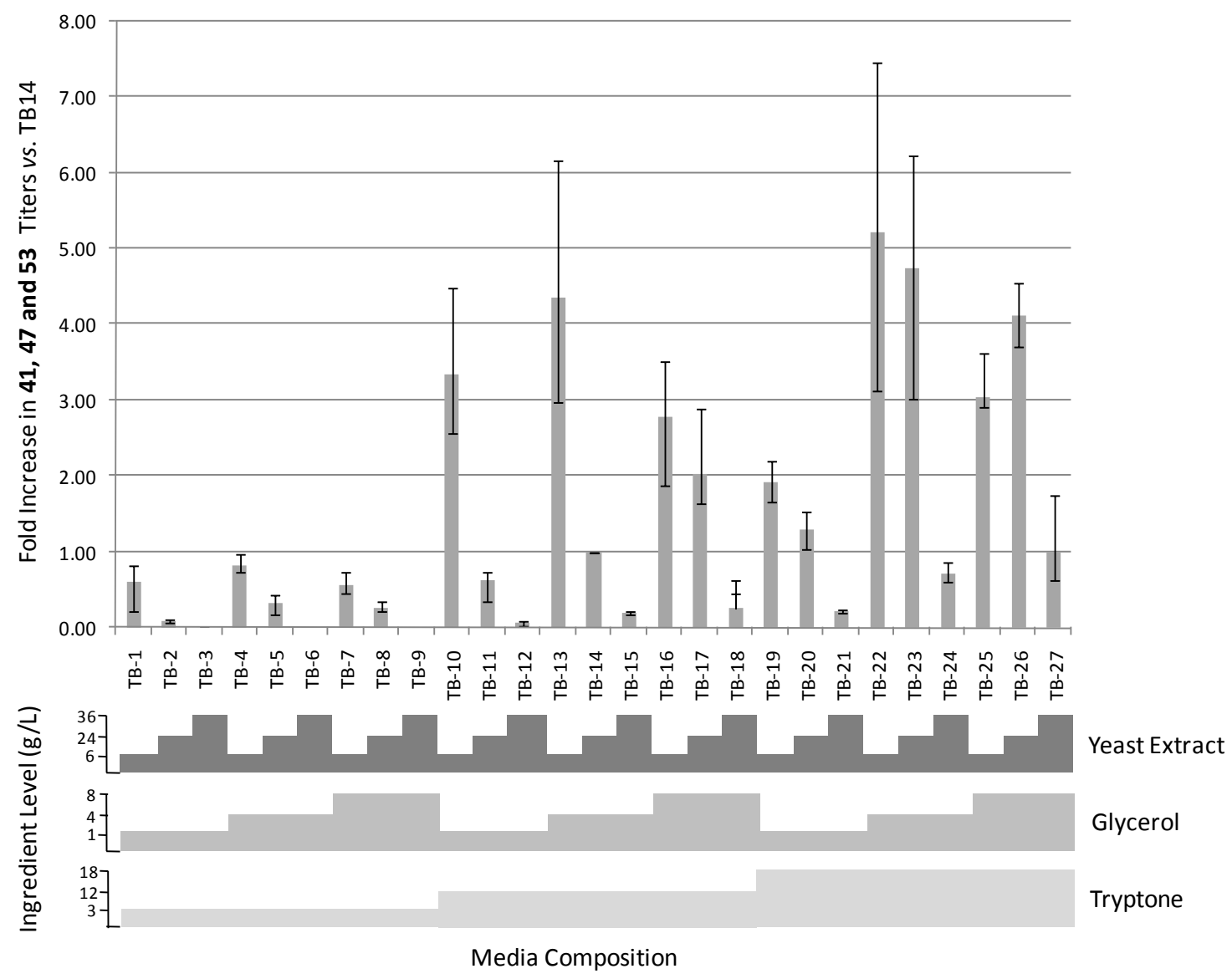




\subsection{Taxonomic Identification of Bacteria Producing 3-Hydroxybutyric Acid Oligomers}

To determine the taxonomic classification of the EC-derived colonies E1-1D5-g, -i, - $j$ and E2-1B1-d, -a , the nearly complete 16S small subunit ribosomal RNA genes were amplified from 3 replicate colonies of each of the 5 isolates by PCR and the resulting amplicons were completely sequenced. Comparison of the 16S rDNA amplicons from the E1-1D5 isolates revealed that they were $100 \%$ identical, indicating that the three isolates were identical clones purified from well D5 of subculture plate 1-1. Comparison of the nearly full length 16S rRNA gene (1480 bp) to sequences contained within the GenBank non-redundant nucleotide database using the BlastN program indicated that the EC isolates shared 1479 out of 1480 residues with a number of Photobacterium damselae strains [24]. Comparison of the 16S rDNA amplicons from the E2-1B1-a and E2-1B1-d isolates also revealed that they were $100 \%$ identical, indicating that these isolates are identical clones purified from well B1 of subculture plate 2-1. Comparison of the nearly full length $16 \mathrm{~S}$ rRNA gene (1547 bp) to sequences contained within the GenBank non-redundant nucleotide database using the BlastN program indicated that the 16S rDNA gene of EC isolates shared more than $98.5 \%$ identity with a number of Vibrio harveyi strains. The partial 16S rRNA gene sequences for $P$. damselae strain E1-1D5 and $V$. harveyi strain E2-1B1 have been deposited in GenBank under accession numbers HM143776 and HM143777, respectively.

\section{Conclusions}

A rapid MWP-based mixed culture strategy was successfully employed to screen more than 1500 small-scale mixed cultures for microbial producers of metabolites detected in organic extracts of the gorgonian coral EC. Small-scale MWP-based culturing paired with rapid UPLC/MS analysis affords an efficient method to not only identify natural products produced in mixed culture but also to evaluate axenic cultures. Inoculation of 1536 wells with EC tissue homogenate and subsequent rapid chemical screening by UPLC/MS resulted in the detection of 2 wells containing elevated quantities of three related metabolites identified in the EC extract. The three metabolites were revealed to be 3-hydroxybutyric acid oligomers containing 6 to 8 monomers by interpretation of NMR and LC/MS data. These compounds have not previously been reported from EC. Two axenic strains of bacteria were isolated from glycerol stocks prepared from the two wells originally exhibiting production, and were subsequently shown to be strains of $P$. damselae and $V$. harveyi via $16 \mathrm{~S}$ rRNA gene sequencing. Both Photobacterium and Vibrio are known to produce polyhydoxybutyrate (PHB) oligomers and polymers and other polyhydroxyalkanoates [25-27]. In bacteria, PHB is commonly encountered as a high molecular weight polymer (150-30,000 monomer units) and is usually accumulated in intracellular light refractive granules when an essential nutrient such as nitrogen or phosphorous is limited in the presence of excess carbon source, and is believed to function as an energy reserve [28,29]. Photobacterium and Vibrio are both ubiquitous marine bacteria belonging to the Vibronacea which are often associated with disease states in a number of marine organisms. The role of these bacteria in EC is not clear at this time; however, these microbes were isolated from tissue exhibiting no outward sign of disease. 
The approach described above to identifying microbial producers of metabolites present in marine invertebrates represents a unique and rapid method which should be applicable to a variety of systems. Traditional strategies have relied on the isolation of axenic cultures from the invertebrate followed by growth under multiple culture conditions in hopes of identifying a microbial producer of the targeted metabolite. The latter approach suffers from a number of drawbacks. Firstly, significant resources are expended isolating, culturing and analyzing microbes which do not possess the capability to produce the compounds of interest. Secondly, culturing of axenic isolates may not provide the biochemical signals normally present in a complex microbial community necessary for the induction of secondary metabolite biosynthesis. Bacteria are well known to employ a number of biochemical signals to control gene expression, and natural product biosynthesis under laboratory conditions has been shown to rely on signaling between different species of a marine bacterial population [30,31]. Screening mixed cultures for metabolite production avoids these potential pitfalls while simultaneously allowing for the subsequent purification of axenic cultures from archived frozen glycerol stocks. The described methodology was also validated as a rapid and cost-effective tool for the preliminary optimization of growth conditions prior to more costly large scale cultures.

\section{Experimental Section}

\subsection{Identification of Secondary Metabolites Present in EC}

Samples of EC ( $5 \mathrm{~kg}$ ) were collected off the coast of Florida at a depth of $10 \mathrm{~m}$ in June 2007 and were extracted several times with a mixture ACN:DCM (1:1). The crude extract was fractionated by flash chromatography on $\mathrm{C} 18$ and the resulting fractions were further purified by normal phase Diol with a step gradient hexane-EtOAc- $\mathrm{MeOH}$ and reversed phase $\mathrm{C} 18$ column chromatography with a $\mathrm{H}_{2} \mathrm{O}-\mathrm{MeOH}-\mathrm{DCM}$ stepwise gradient system. All the fractions were analyzed by UPLC (Thermo Scientific, Accela) coupled to an ELSD (Sedere, Sedex LT-ELSD Model 80LT) and mass spectrometer (Thermo Scientific, LTQ ion trap) with a standard gradient from $5 \%$ ACN in $\mathrm{H}_{2} \mathrm{O}(0.1 \%$ formic acid in both eluents) to $100 \% \mathrm{ACN}$ in 6 minutes.

\subsection{Chemical Screening of MWP Mixed Cultures}

E. caribaeorum was collected at Boca Raton, Florida in February 2007 by SCUBA at a depth of $13 \mathrm{~m}$. Coral specimens were individually flash frozen with liquid nitrogen and subsequently stored at $-80{ }^{\circ} \mathrm{C}$. Flash-frozen coral $(1 \mathrm{~g})$ was homogenized in $50 \mathrm{~mL}$ artificial sea water (ASW) using a commercial Waring blender. The contents were filtered through four layers of sterile cheesecloth and $17.5 \mu \mathrm{L}$ of coral homogenate was used to inoculate each well of 4 enrichment plates (96 MWPs) containing $1.7 \mathrm{~mL}$ of culture broth per well. The enrichment plates were composed of gradients of $\mathrm{pH}$, salt, nitrogen source, carbon source and antibiotics (penicillin G or kanamycin) as illustrated in the Table 1. All media were prepared with deionized water and autoclaved to sterilize the medium unless otherwise noted. Media compositions were as follows: Emerson medium-yeast extract (10.0 g/L), beef extract (44 g/L), peptone (4 g/L), $\mathrm{NaCl}(25 \mathrm{~g} / \mathrm{L})$, glucose (10 g/L, added post sterilization) [32]; Artificial Sea Water (ASW) medium - Instant Ocean ${ }^{\mathrm{TM}}(36 \mathrm{~g} / \mathrm{L})$ and glucose or glycerol $(4 \mathrm{~g} / \mathrm{L}$, added

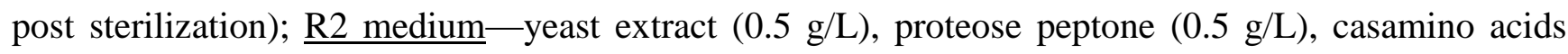


(0.5 g/L), soluble starch $(0.5 \mathrm{~g} / \mathrm{L})$, sodium pyruvate $(0.3 \mathrm{~g} / \mathrm{L}), \mathrm{K}_{2} \mathrm{HPO}_{4}(0.3 \mathrm{~g} / \mathrm{L}), \mathrm{MgSO}_{4}(0.05 \mathrm{~g} / \mathrm{L})$, glucose $(0.5 \mathrm{~g} / \mathrm{L}$, added post sterilization), pH 7.2 [33]; ISP1 medium-pancreatic digest of casein ( $5 \mathrm{~g} / \mathrm{L})$, yeast extract (3 g/L), nalidixic acid $\left(10 \mu \mathrm{g} / \mathrm{mL}\right.$ post sterilization) [34]; M9 media-Difco ${ }^{\text {TMM9 }}$ Minimal Salts $5 \mathrm{X}$ powder $(11.28 \mathrm{~g} / \mathrm{L})$ and glycerol or glucose or arabinose $(4 \mathrm{~g} / \mathrm{L}$, added post sterilization) [35]; $\underline{\mathrm{MB}}$-Difco ${ }^{\mathrm{TM}}$ Marine Broth 2216 (37.4 g/L) [36]; $1 / 10 \mathrm{MB}$-Difco ${ }^{\mathrm{TM}}$ Marine Broth 2216 (3.74 g/L), NaCl (18 g/L); NB-EMD Nutrient Broth powder (8 g/L) [37]; 1/10NB-EMD Nutrient Broth powder $(0.8 \mathrm{~g} / \mathrm{L})$; NB/SW-EMD Nutrient Broth powder $(8 \mathrm{~g} / \mathrm{L})$, Instant Ocean ${ }^{\mathrm{TM}}$ (36 g/L); NB 0.5\% butanol-EMD Nutrient Broth powder (8 g/L), butanol (5 mL/L); $\underline{\text { LB}}$ —EMD LB Broth Miller powder (25 g/L); $\underline{\text { TB}}$-EMD TB powder (47.6 g/L) [35]. Buffered NB, 1/10 NB, MB and $1 / 10 \mathrm{MB}$ were generated by preparing the media as described above with the addition of the following $0.1 \mathrm{M} \mathrm{Na}_{2} \mathrm{HPO}_{4} \cdot 7 \mathrm{H}_{2} \mathrm{O}$ and $0.1 \mathrm{M} \mathrm{NaH} \mathrm{PO}_{4} \cdot \mathrm{H}_{2} \mathrm{O}$ per litre of media; $\mathrm{pH} 5.8,7.9 \mathrm{~mL} 0.1 \mathrm{M}$ $\mathrm{Na}_{2} \mathrm{HPO}_{4} \cdot 7 \mathrm{H}_{2} \mathrm{O}$ and $92.1 \mathrm{~mL} 0.1 \mathrm{M} \mathrm{NaH} \mathrm{PO}_{4} \cdot \mathrm{H}_{2} \mathrm{O} ; \mathrm{pH}$ 6.5, $30.3 \mathrm{~mL} 0.1 \mathrm{M} \mathrm{Na}_{2} \mathrm{HPO}_{4} \cdot 7 \mathrm{H}_{2} \mathrm{O}$ and $69.7 \mathrm{~mL} 0.1 \mathrm{M} \mathrm{NaH} \mathrm{PO}_{4} \cdot \mathrm{H}_{2} \mathrm{O} ; \mathrm{pH} 7.2,68.4 \mathrm{~mL} 0.1 \mathrm{M} \mathrm{Na} \mathrm{HPO}_{4} \cdot 7 \mathrm{H}_{2} \mathrm{O}$ and $3.16 \mathrm{~mL} 0.1 \mathrm{M}$ $\mathrm{NaH}_{2} \mathrm{PO}_{4} \cdot \mathrm{H}_{2} \mathrm{O}$; pH 8.0, $93.2 \mathrm{~mL} 0.1 \mathrm{M} \mathrm{Na}_{2} \mathrm{HPO}_{4} \cdot 7 \mathrm{H}_{2} \mathrm{O}$ and $6.8 \mathrm{~mL} 0.1 \mathrm{M} \mathrm{NaH}_{2} \mathrm{PO}_{4} \cdot \mathrm{H}_{2} \mathrm{O}$. Penicillin $\mathrm{G}$ and kanamycin were added to wells as at a concentration of $10 \mu \mathrm{g} / \mathrm{mL}$ and $50 \mu \mathrm{g} / \mathrm{mL}$, respectively. Following inoculation, the four enrichment plates were covered with a sterile breathable nylon adhesive membrane and incubated for 7 days under the following conditions: Enrichment Plate 1, $30{ }^{\circ} \mathrm{C} / 150 \mathrm{rpm}$; Enrichment Plate 2, $37{ }^{\circ} \mathrm{C} / 150 \mathrm{rpm}$; Enrichment Plate 3, $30{ }^{\circ} \mathrm{C} /$ static; Enrichment Plate 4, $37{ }^{\circ} \mathrm{C} /$ static. Each enrichment plate was then subcultured using a 96-pin replicator (Boekel Scientific, USA) in four different 96 MWPs (Table 1). The first plate possessed the same layout as the enrichment plate (subculture plate 1) and the three other plates were uniformly filled with TB (Subculture Plate 2), MB (Subculture Plate 3) or 1/10MB (Subculture Plate 4). The sixteen resulting subculture plates were incubated static at $30{ }^{\circ} \mathrm{C}$ for 14 days. Prior to harvesting, each plate was archived by transferring $100 \mu \mathrm{L}$ from each well to shallow 96 MWPs and mixed with $100 \mu \mathrm{L} 50 \%$ glycerol (w/v) and stored at $-80{ }^{\circ} \mathrm{C}$. The plates were centrifuged at $3000 \times g$ at $24{ }^{\circ} \mathrm{C}$ for $20 \mathrm{~min}$, and $1 \mathrm{~mL}$ of supernatant was transferred to a new 96 MWP and dried under vacuum using a Genevac EZ-2 instrument (Genevac Inc, USA). Sterile deionized $\mathrm{H}_{2} \mathrm{O}(100 \mu \mathrm{L})$ was added to the dried residues and incubated for $10 \mathrm{~min}$ at room temperature with occasional shaking. ACN (900 $\mu \mathrm{L})$ was added to the rehydrated residues and mixed thoroughly by repeated aspiration through a $1 \mathrm{~mL}$ pipette tip. The resulting extract was centrifuged at $1000 \times g$ for $5 \mathrm{~min}$. The supernatant was transferred to a new plate, dried under vacuum and dissolved in $100 \mu \mathrm{L}$ of $\mathrm{MeOH}$. Extracts were analyzed by UPLC/MS using the same method used to generate the EC target-molecule library.

\subsection{Chemical Screening of Axenic MWP Cultures}

A portion $(5-10 \mu \mathrm{L})$ of mixed culture glycerol stock of cultures which showed production of metabolites identified in EC extracts were diluted 50 fold in TB and LB liquid media and plated on TB agar (media prepared as for liquid media described above but amended with $15 \mathrm{~g} / \mathrm{L}$ agar) and incubated at $30{ }^{\circ} \mathrm{C}$ for 7 days. Two representative colonies of each morphological type were used to inoculate the wells of a new MWP containing $1.7 \mathrm{~mL}$ of the following media: NB, LB, TB, M9 glycerol and ASW glycerol. Plates were incubated static at $30{ }^{\circ} \mathrm{C}$ for 14 days. Plates were extracted and analyzed in an identical fashion to that used for the original mixed culture plates. 


\subsection{TB Media Optimization Study}

The standard TB medium formulation consists of tryptone $(12 \mathrm{~g} / \mathrm{L})$, yeast extract $(24 \mathrm{~g} / \mathrm{L})$, glycerol $(4 \mathrm{~g} / \mathrm{L}), \mathrm{K}_{2} \mathrm{HPO}_{4}(9.4 \mathrm{~g} / \mathrm{L})$ and $\mathrm{KH}_{2} \mathrm{PO}_{4}(2.2 \mathrm{~g} / \mathrm{L})$. All media formulations contained identical concentrations of $\mathrm{K}_{2} \mathrm{HPO}_{4}$ and $\mathrm{KH}_{2} \mathrm{PO}_{4}$ while the levels of tryptone, yeast extract and glycerol were varied between low, mid and high levels (trypone: low $3 \mathrm{~g} / \mathrm{L}$, mid $12 \mathrm{~g} / \mathrm{L}$, high $18 \mathrm{~g} / \mathrm{L}$; yeast extract: low $6 \mathrm{~g} / \mathrm{L}$, mid $24 \mathrm{~g} / \mathrm{L}$, high $36 \mathrm{~g} / \mathrm{L}$; glycerol: low $1 \mathrm{~g} / \mathrm{L}$, mid $4 \mathrm{~g} / \mathrm{L}$, high $8 \mathrm{~g} / \mathrm{L}$ ). All media were autoclaved at $121{ }^{\circ} \mathrm{C}$ for $15 \mathrm{~min}$ and $1.5 \mathrm{~mL}$ was dispensed in the wells of sterile MWPs. To prepare inocula for MWP cultures, three individual isolates (E1-1D5-g,-i,and -j) were used to inoculate $10 \mathrm{~mL}$ of TB (standard formulation) medium and cultured for $16 \mathrm{hr}$ at $30{ }^{\circ} \mathrm{C}$ and $150 \mathrm{rpm}$. A portion $(5 \mu \mathrm{L})$ of these cultures were used to inoculate each well of the MWP. Duplicate MWP cultures were incubated at $30{ }^{\circ} \mathrm{C}$ under static conditions for 14 days and were extracted and analyzed as described above for mixed microbial cultures.

\subsection{Structure Determination}

EC crude extract (100g) was partitioned between $\mathrm{MeOH}$ and hexane. After evaporation under vacuum, the $\mathrm{MeOH}$ extract (42 g) was consecutively fractionated by flash chromatography on $\mathrm{C} 18$ (Phenomenex, Sepra C18-T (50 $\mu \mathrm{m}, 135 \AA$ )) with a step gradient $\mathrm{H}_{2} \mathrm{O}: \mathrm{MeOH}(9: 1), \mathrm{H}_{2} \mathrm{O}: \mathrm{MeOH}(5: 5)$, $\mathrm{H}_{2} \mathrm{O}: \mathrm{MeOH}$ (2:8), ACN, acetone and DCM:MeOH (1:1) and flash chromatography on Diol with a step gradient of hexane to EtOAc to $\mathrm{MeOH}$. The fraction $(188 \mathrm{mg}$ ) containing the target compounds were further fractionated using an automated C18 chromatography system (Teledyne, Combiflash Rf) and compound 47 was finally purified by reversed phase HPLC (Phenomenex luna C18 5u, $250 \times 10 \mathrm{~mm}$ ) using an isocratic gradient $\mathrm{H}_{2} \mathrm{O}[0.1 \% \mathrm{FA}]$ : $\mathrm{ACN}[0.1 \% \mathrm{FA}]$ (30:70) to yield to a white powder (2.9 mg). Compound 47 was characterized by 1D and 2D NMR analysis (Bruker Avance $600 \mathrm{MHz}$ ) as well as tandem mass spectroscopy and identified as an oligomer containing seven 3-hydroxybutyric acid units. ${ }^{1} \mathrm{H}$ NMR $\left(300 \mathrm{MHz}, \mathrm{CDCl}_{3}\right) \delta 5.30(1 \mathrm{H}, \mathrm{m}), 2.63(1 \mathrm{H}, \mathrm{dd}, J=7.7,15.5 \mathrm{~Hz}), 2.48(1 \mathrm{H}$, dd, $J=5.4,15.5 \mathrm{~Hz}), 1.29(3 \mathrm{H}, \mathrm{d}, J=6.4 \mathrm{~Hz}) ;{ }^{13} \mathrm{C} \mathrm{NMR}\left(75 \mathrm{MHz}, \mathrm{CDCl}_{3}\right) \delta 169.4$ (s), 67.8 (d), 40.9 (d), 19.9 (q). Due to observed differences of 86 amu in the mass spectra, compounds $\mathbf{4 1}$ and $\mathbf{5 3}$ were determined to possess six and eight 3-hydroxybutyric acid units, respectively.

\section{6. $16 S$ rDNA Sequencing}

16S ribosomal RNA gene fragments were amplified using the GoTaq Green Master Mix PCR kit (Promega) according to the manufacturer's specifications. Reactions $(50 \mu \mathrm{L})$ contained $0.5 \mu \mathrm{M}$ of each of the universal bacterial 16S rRNA primers E8F (5'-AGAGTTGATCCTGGCTCAG) and E1541R (5'-AAGGAGGTGATCCANCCRCA) [38]. Template DNA was prepared by dispersing actively growing single colonies picked from TB agar plates in $50 \mu \mathrm{L}$ of PCR grade DMSO. A portion of the DMSO cell suspension $(1.25 \mu \mathrm{L})$ was added to each PCR reaction resulting in a final DMSO concentration of $5 \%$. Thermal cycling parameters consisted of an initial denaturing step of 3 min at $94{ }^{\circ} \mathrm{C}$ and 30 cycles consisting of $1 \mathrm{~min}$ at $94{ }^{\circ} \mathrm{C}, 1 \mathrm{~min}$ at $54{ }^{\circ} \mathrm{C}$ and $2 \mathrm{~min}$ at $72{ }^{\circ} \mathrm{C}$ and a final extension step at $72{ }^{\circ} \mathrm{C}$ for $10 \mathrm{~min}$. PCR products were purified using the DNA Clean and Concentrator-5 kit (Zymo Research Corporation). Purity and concentration of purified PCR products 
were assessed by agarose gel electrophoresis. PCR products were sequenced by The Centre for Applied Genomics (Toronto, CA).

\section{Acknowledgements}

The authors gratefully acknowledge financial support from NSERC, the Canada Research Chair Program, the University of Prince Edward Island, Atlantic Canada Opportunities Agency (Atlantic Innovation Fund) and the Jeanne and Jean-Louis Lévesque Foundation. We also acknowledge the technical assistance of S. Berger in the preparation of media.

\section{References}

1. Newman, D.J.; Cragg, G.M.; Snader, K.M. Natural Products as Sources of New Drugs over the Period 1981-2002. J. Nat. Prod. 2003, 66, 1022-1037.

2. Newman, D.J.; Cragg, G.M. Natural Products as Sources of New Drugs over the Last 25 Years. J. Nat. Prod. 2007, 70, 461-477.

3. Berrue, F.; Kerr, R.G. Diterpenes from Gorgonian Corals. Nat. Prod. Rep. 2009, 26, 681-710.

4. Blunt, J.W.; Copp, B.R.; Munro, M.H.G.; Northcote, P.T.; Prinsep, M.R. Marine Natural Products. Nat. Prod. Rep. 2010, 27, 165-237.

5. Marris, E. Marine Natural Products: Drugs from the Deep. Nature 2006, 443, 904-905.

6. Simmons, T.L.; Andrianasolo, E.; McPhail, K.; Flatt, P.; Gerwick, W.H. Marine Natural Products as Anticancer Drugs. Mol. Cancer Ther. 2005, 4, 333-342.

7. Simmons, T.L.; Coates, R.C.; Clark, B.R.; Engene, N.; Gonzalez, D.; Esquenazi, E.; Dorrestein, P.C.; Gerwick, W.H. Biosynthetic Origin of Natural Products Isolated from Marine Microorganism-Invertebrate Assemblages. Proc. Natl. Acad. Sci. USA 2008, 105, 4587-4594.

8. Molinski, T.F.; Dalisay, D.S.; Lievens, S.L.; Saludes, J.P. Drug Development from Marine Natural Products. Nat. Rev. Drug Discov. 2009, 8, 69-85.

9. Piel, J. Bacterial Symbionts: Prospects for the Sustainable Production of Invertebrate-Derived Pharmaceuticals. Curr. Med. Chem. 2006, 13, 39-50.

10. Hildebrand, M.; Waggoner, L.E.; Lim, G.E.; Sharp, K.H.; Ridley, C.P.; Haygood, M.G. Approaches to Identify, Clone, and Express Symbiont Bioactive Metabolite Genes. Nat. Prod. Rep. 2004, 21, 122-142.

11. Kennedy, J.; Marchesi, J.R.; Dobson, A.D.W. Metagenomic Approaches to Exploit the Biotechnological Potential of the Microbial Consortia of Marine Sponges. Appl. Microbiol. Biotechnol. 2007, 75, 11-20.

12. Oclarit, J.M.; Okada, H.; Ohta, S.; Kaminura, K.; Yamaoka, Y.; Iizuka, T.; Miyashiro, S.; Ikegami, S. Anti-Bacillus Substance in the Marine Sponge, Hyatella Species, Produced by an Associated Vibrio Species Bacterium. Microbios 1994, 78, 7-16.

13. Shigemori, H.; Bae, M.A.; Yazawa, K.; Sasaki, T.; Kobayashi, J. Alteramide A, a New Tetracyclic Alkaloid from a Bacterium Alteromonas Sp. Associated with the Marine Sponge Halichondria Okadai. J. Org. Chem. 1992, 57, 4317-4320.

14. Stierle, A.C.; Cardellina, J.H., II; Singleton, F.L. A Marine Micrococcus Produces Metabolites Ascribed to the Sponge Tedania Ignis. Experientia 1988, 44, 1021. 
15. Duetz, W.A. Microtiter Plates as Mini-Bioreactors: Miniaturization of Fermentation Methods. Trends Microbiol. 2007, 15, 469-475.

16. Look, S.A.; Fenical, W.; Van, E., Donna; Clardy, J. Erythrolides: Unique Marine Diterpenoids Interrelated by a Naturally Occurring Di-Ï€-Methane Rearrangement. J. Am. Chem. Soc. 1984, 106, 5026-5027.

17. Fenical, W.; Pawlik, J.R. Defensive Properties of Secondary Metabolites from the Caribbean Gorgonian Coral Erythropodium Caribaeorum. Mar. Ecol. Prog. Ser. 1991, 75, 1-8.

18. Dookran, R.; Maharaj, D.; Mootoo, B.S.; Ramsewak, R.; McLean, S.; Reynolds, W.F.; Tinto, W.F. Diterpenes from the Gorgonian Coral Erythropodium Caribaeorum from the Southern Caribbean. J. Nat. Prod. 1993, 56, 1051-1056.

19. Cinel, B.; Roberge, M.; Behrisch, H.; van Ofwegen, L.; Castro, C.B.; Andersen, R.J. Antimitotic Diterpenes from Erythropodium Caribaeorum Test Pharmacophore Models for Microtubule Stabilization. Org. Lett. 2000, 2, 257-260.

20. Britton, R.; Roberge, M.; Berisch, H.; Andersen, R.J. Antimitotic Diterpenoids from Erythropodium Caribaeorum: Isolation Artifacts and Putative Biosynthetic Intermediates. Tetrahedron Lett. 2001, 42, 2953-2956.

21. Plumb, R.; Castro-Perez, J.; Granger, J.; Beattie, I.; Joncour, K.; Wright, A. Ultra-Performance Liquid Chromatography Coupled to Quadrupole-Orthogonal Time-of-Flight Mass Spectrometry. Rapid Commun. Mass Spectrom. 2004, 18, 2331-2337.

22. Toyo'oka, T. Determination Methods for Biologically Active Compounds by Ultra-Performance Liquid Chromatography Coupled with Mass Spectrometry: Application to the Analyses of Pharmaceuticals, Foods, Plants, Environments, Metabonomics, and Metabolomics. J. Chromatogr. Sci. 2008, 46, 233-247.

23. Yao, S.; Wu, T.; Li, X.; Tu, B.; Song, H. Ten Years of Research into Phytomedicines AnalysisAn Era in New Technologies and Methods. Curr. Pharm. Anal. 2010, 6, 269-288.

24. Altschul, S.F.; Madden, T.L.; Schaffer, A.A.; Zhang, J.; Zhang, Z.; Miller, W.; Lipman, D.J. Gapped BLAST and PSI-BLAST: A New Generation of Protein Database Search Programs. Nucleic Acids Res. 1997, 25, 3389-3402.

25. Sun, W.; Teng, K.; Meighen, E. Detection of Poly(3-Hydroxybutyrate) Granules by Electron Microscopy of Vibrio Harveyi Stained with Malachite Green. Can. J. Microbiol. 1995, 41, 131-137.

26. Kimura, B.; Hokimoto, S.; Takahashi, H.; Fujii, T. Photobacterium Histaminum Okuzumi et al. 1994 is a Later Subjective Synonym of Photobacterium Damselae Subsp. Damselae (Love et al. 1981) Smith et al. 1991. Int. J. Syst. Evol. Microbiol. 2000, 50, 1339-1342.

27. Smith, S.K.; Sutton, D.C.; Fuerst, J.A.; Reichelt, J.L. Evaluation of the Genus Listonella and Reassignment of Listonella Damsela (Love et al.) MacDonell and Colwell to the Genus Photobacterium as Photobacterium Damsela Comb. Nov. with an Emended Description. Int. J. Syst. Bacteriol. 1991, 41, 529-534.

28. Lee, S.Y. Plastic Bacteria? Progress and Prospects for Polyhydroxyalkanoate Production in Bacteria. Trends Biotechnol. 1996, 14, 431-438.

29. Zinn, M.; Witholt, B.; Egli, T. Occurrence, Synthesis and Medical Application of Bacterial Polyhydroxyalkanoate. Adv. Drug Delivery Rev. 2001, 53, 5-21. 
30. Williams, P. Quorum Sensing, Communication and Cross-Kingdom Signalling in the Bacterial World. Microbiology 2007, 153, 3923-3938.

31. Angell, S.; Bench, B.J.; Williams, H.; Watanabe Coran, M.H. Pyocyanin Isolated from a Marine Microbial Population: Synergistic Production between Two Distinct Bacterial Species and Mode of Action. Chem. Biol. 2006, 13, 1349-1359.

32. Medsker, L.L.; Jenkins, D.; Thomas, J.F.; Koch, C. Odorous Compounds in Natural Waters. 2-Exo-Hydroxy-2-Methylbornane, the Major Odorous Compound Produced by several Actinomycetes. Environ. Sci. Technol. 1969, 3, 476-477.

33. Reasoner, D.J.; Geldreich, E.E. A New Medium for the Enumeration and Subculture of Bacteria from Potable Water. Appl. Environ. Microbiol. 1985, 49, 1-7.

34. Shirling, E.B.; Gottlieb, D. Methods for Characterization of Streptomyces Species. Int. J. Syst. Bacteriol. 1966, 16, 313-340.

35. Sambrook, J.; Fritsch, E.F.; Maniatis, T. Molecular Cloning: A Laboratory Manual, 2nd ed.; Cold Spring Harbor Laboratory: Cold Spring Harbor, NY, USA, 1989.

36. ZoBell, C.E. Studies on Marine Bacteria. I. the Cultural Requirements of Heterotrophic Aerobes. J. Mar. Res. 1941, 4, 42-75.

37. Marshall, R.T. Standard Methods for the Examination of Dairy Products, 16th ed.; American Public Health Association: Washington, D.C., USA, 1993.

38. Baker, G.C.; Smith, J.J.; Cowan, D.A. Review and Re-Analysis of Domain-Specific 16S Primers. J. Microbiol. Methods 2003, 55, 541-555.

(C) 2011 by the authors; licensee MDPI, Basel, Switzerland. This article is an open access article distributed under the terms and conditions of the Creative Commons Attribution license (http://creativecommons.org/licenses/by/3.0/). 